\title{
Characterisation and Antibacterial Properties of Novel Biodegradable Films Based on Alginate and Roselle (Hibiscus sabdariffa L.) Extract
}

\author{
Gulsum Aydin $^{1}{ }^{10} \cdot$ Elif Busra Zorlu ${ }^{1}$
}

Received: 18 August 2021 / Accepted: 1 February 2022 / Published online: 18 February 2022

(c) The Author(s), under exclusive licence to Springer Nature B.V. 2022

\begin{abstract}
Composite films were prepared with alginate and roselle extract (HE) at different concentrations (1\%,3\%, and 5\% w/v) via solvent casting technique and analyzed in terms of physical, mechanical, and antibacterial properties. The incorporation of $\mathrm{HE}$ into alginate films resulted in rough and heterogeneous surface characteristics with increasing concentrations of HE. The thickness and water vapor permeability of alginate-HE composite films were significantly higher $(p<0.05)$ compared to pure alginate films. Moreover, water content, solubility, swelling, tensile strength, and elongation at break value of the composite films decreased $(p<0.05)$ with increasing concentrations of the extract. FTIR spectra revealed shifts and intensity variations in the composite films and the formation of new peaks suggesting a possible interaction between alginate and HE. Alginate-HE films exhibited good antibacterial activity against Gram-positive (Staphylococcus aureus and Bacillus subtilis) and Gram-negative (Escherichia coli and Klebsiella pneumoniae) bacteria. The antibacterial effect of the films, more pronounced against Gram-positive bacteria, increased with higher amounts of HE. The resulting films may be utilised as new biodegradable, antibacterial films in the food packaging industry to prolong shelf life and preserve food safety.
\end{abstract}

\section{Graphical Abstract}

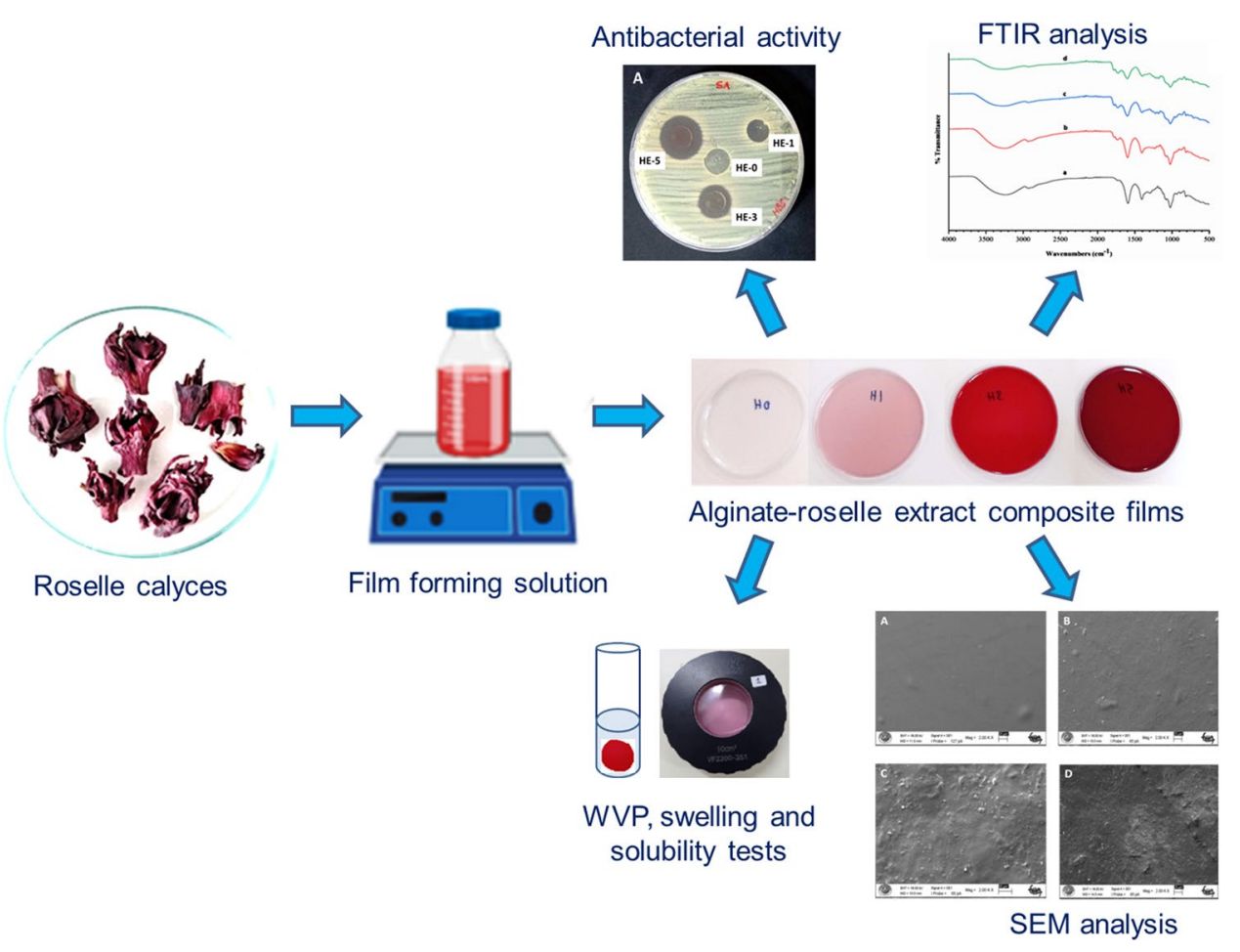

Extended author information available on the last page of the article 
Keywords Alginate film $\cdot$ Antibacterial $\cdot$ Food packaging $\cdot$ Hibiscus sabdariffa

\section{Statement of Novelty}

Global plastic contamination is a severe environmental problem. Biopolymers of natural origin are environmentally friendly, renewable, non-toxic, biodegradable, and biocompatible materials to replace non-biodegradable and nonrenewable synthetic polymers for producing active packaging materials. In this context, films were prepared with alginate and roselle extract and antimicrobial, mechanical, and physical properties of the films were evaluated. Plant extracts have been extensively investigated as renewable and natural sources of antimicrobial compounds. Extract of roselle calyces incorporated in alginate films conferred high antibacterial activity against both Gram-negative and Grampositive bacteria suggesting that these films are promising to be used as a natural and degradable biopolymer-based composite packaging material that may improve the quality and safety of foods. To the knowledge of the authors this is the first report of an alginate-based edible film incorporated with roselle extract.

\section{Introduction}

Global plastic contamination is a severe environmental problem, and a tremendous increase is reported in 2020 due to the utilization of personal protective materials for the COVID-19 pandemic [1]. A total of 8.3 billion tons of plastics have been manufactured since the advent of this miracle material. Besides its significant benefits, 6.3 billion tons of synthetic plastics have become waste resulting in serious damage to the environment [2]. The non-biodegradable and non-renewable character of petroleum-based synthetic polymers has motivated the use of natural biopolymers. Biopolymers such as polysaccharides, lipids, and proteins are environmentally friendly, renewable, biodegradable, non-toxic, and biocompatible materials. The eco-friendly nature of these materials renders natural biopolymers good alternatives to synthetic polymers to produce edible and biodegradable packaging materials. The utilization of natural biopolymer-based packaging materials preserves the quality of foods and prolongs their shelf life besides reducing the consumption of petroleum-based plastics [3-5].

Edible films or coatings are materials less than $0.3-\mathrm{mm}$ thick that are used for fresh and minimally processed foods. The films or coatings are formed via the dispersion of biopolymers and various additives in an aqueous media. Complete dissolution and dispersion of the film-forming components are essential for the fabrication of a homogeneous and continuous film matrix. During film preparation, the film forming solutions are usually filtered to remove undissolved solutes and sonicated to remove the bubbles to ensure the homogeneity and continuity of the polymer matrix $[6,7]$. The resulting films should meet the main characteristics of traditional packaging such as antimicrobial and antioxidant activity, gas/moisture barrier property, protection against UV light, biodegradability, and barrier against mechanical damage. The appropriate selection of packaging material is crucial to guarantee the safety and quality of food as it affects the physicochemical, functional, and organoleptic characteristics of the food $[8,9]$. Biopolymers such as chitosan $[6,10,11]$, starch [12], cellulose [13, 14], and alginate [15-17] are among the most studied materials for the fabrication of food packagings.

Among natural polymers, alginate has been considered a film-based material due to its excellent film-forming capacity, non-toxic nature, and unique colloidal properties. It is a natural, linear polysaccharide generally synthesized by brown seaweeds, including Laminaria hyperborean, Macrocystis pyrifera, and Ascophyllum nodosum. Alginate is also produced by bacteria such as Azotobacter and Pseudomonas with physical properties and chemical structure that is well defined compared to the seaweed-originated alginates [18]. Alginate is a family of linear copolymers composed of $\beta$-Dmannuronate $(\mathrm{M})$ and $\alpha$-L-guluronate $(\mathrm{G})$ residues linked by 1-4 glycosidic bonds. The blocks can contain homopolymeric residues (MMMM or GGGG) or alternating residues (MGMGMG). Alginates obtained from different sources differ in molecular weight, length of each block, $M$ and $\mathrm{G}$ contents, and their distribution in the polymeric chain, significantly influencing its chemical, physical, and gelling properties and also the resultant hydrogels' [15]. Alginate hydrogels are generally produced by external gelation using divalent cations (i.e., $\mathrm{Ca}^{2+}$ ) as cross-linking agents. $\mathrm{G}$ blocks of alginate chains aid in intermolecular cross-linking with the cation to form the gel network. Although calcium chloride $\left(\mathrm{CaCl}_{2}\right)$ is one of the widely used cross-linking agents, its high solubility in aqueous environments causes fast and uncontrolled gelation limiting its extensive use. Calcium sulfate $\left(\mathrm{CaSO}_{4}\right)$ and calcium carbonate $\left(\mathrm{CaCO}_{3}\right)$ have lower solubility in aqueous solutions, and they are alternatively used to slow and control the gelation rate. Gradual gelation of the alginate solution ensures higher mechanical integrity and more uniform structures [19].

Alginate films are used in many applications such as drug delivery systems, tissue engineering, food packaging, and wound dressing. In the last decades, alginate-based films have been used broadly as an alternative to synthetic packaging. Increasing consumer demands for more natural and 
healthier foods accelerated studies on edible films produced from natural biopolymers [20]. Food spoilage caused by bacteria such as Escherichia coli, Staphylococcus aureus, and Bacillus cereus may result in severe foodborne diseases. Therefore, preventing microbial spoilage contributes to ensuring the safety and quality of foods and extending shelf life. Sodium benzoate, sodium nitrite, and sorbic acid are commonly used synthetic antimicrobials to prevent microbial food spoilage. However, public concern about the health risks and long-term toxicity of these agents has been restricted their extensive use [21].

A tremendous amount of research is focused on natural active agents such as bioactive peptides and protein hydrolysates from food proteins, plant extracts, plant-derived essential oils, and bacteriocins as renewable and natural sources of antimicrobial agents [5]. Instead of directly applying antimicrobial compounds to food products, they are incorporated into edible coatings and films to obtain a gradual release of the agents. These controlled release systems regulate the diffusion of the antimicrobial agent to keep a high concentration of active compounds on the surface of food products for a prolonged period. Active agents may prevent bacterial growth and thus microbiological food spoilage $[21,22]$. In this context, various studies were conducted to produce alginate-based edible films and coatings containing various plant extracts and/or essential oils as antimicrobial agents. Senturk Parreidt et al. [15] summarized some of these studies and concluded that alginate is an effective matrix to carry the antimicrobial agents. Alginate films and coatings carrying plant extracts such as gallnut extract [21], olive leaves extract [16], ginseng extract [23], Stryphnodendron adstringens extract [24], and black chokeberry extract [25] were reported in the literature.

In this study, roselle (Hibiscus sabdariffa L.) extract was used to obtain antibacterial alginate films. Roselle, an annual tropical shrub, is a member of the family Malvaceae. It is native to tropical Africa and also cultivated in Central and South America and Southeast Asia [26]. Roselle calyces are used in the food industry to produce hot and cold herbal infusions, fermented beverages, sauces, juices, jellies, jams, and baked goods [27]. The extract of flowers is also used in folk medicine against hypertension, liver diseases, and fever [28]. The extracts are deemed GRAS (generally recognized as safe) as a food additive by the U.S. Food and Drug Administration (21 CFR 172.510). The calyces are rich in bioactive molecules such as anthocyanins, organic acids, alkaloids, phenolic acids, and saponins. These bioactive compounds confer antioxidant, cardioprotective, antidiabetic, anticancer, and antimicrobial properties to roselle extracts [29]. The incorporation of antimicrobial and antioxidant roselle extracts enables the production of natural and biodegradable packaging materials that extend the shelflife and ensure foods' quality and safety. Previously roselle extract was added to carboxymethylcellulose (CMC) [13], tapioca starch [30], corn starch [26, 31], gum arabic [27], polyvinyl alcohol [14], and chitosan/polyvinyl alcohol [32] based polymer matrices to produce biodegradable films.

This research aimed to examine the antimicrobial potential and functional properties [mechanical, water vapor permeability (WVP), microstructure, and solubility] of films prepared with alginate and roselle extract at different ratios. The potential of the films to be a biodegradable and natural alternative as a food packaging material was evaluated. To the knowledge of the authors, this is the first research on alginate-based edible film incorporated with roselle extract.

\section{Materials and Methods}

\section{Materials}

Sodium alginate derived from seaweed and $\mathrm{CaCO}_{3}$ were purchased from a local food ingredient supplier (Katki Dunyasi, Turkey). Calyces of roselle (Bagdat Baharat, Turkey), glucono delta-lactone (GDL, Smart Kimya, Turkey), Nutrient broth (Merck, Germany), bacteriological agar (Himedia, India), and glycerol (Sigma-Aldrich, Germany) were utilized in the present study. Distilled water was used throughout the experiments.

\section{Extract Preparation}

The extract was prepared by the decoction method described by Rasheed et al. [33] with slight modifications. The roselle calyces were ground using a blender (Sinbo SCM-2914, Turkey) and dispersed in distilled water (10\% w/v). The calyces were boiled in hot water for $10 \mathrm{~min}$ and subsequently, rest at room temperature for $10 \mathrm{~min}$. After the solution had cooled down, it was filtered twice using standard medium pore filter paper to remove calyx particles and stored at $4{ }^{\circ} \mathrm{C}$ until use.

\section{Preparation of Alginate-Based Films}

Alginate-based films were prepared via the solvent casting method. The desired amount of HE was added into distilled water to achieve $1 \%, 3 \%$, and $5 \%$ HE solutions and stirred for ten minutes using a magnetic stirrer. Then $1.5 \%(\mathrm{w} / \mathrm{v})$ sodium alginate was added to each solution, and four filmforming dispersions were obtained, as depicted in Table 1. The solutions were stirred until a homogenous mixture was obtained. Glycerol ( $0.2 \mathrm{~g} / \mathrm{g}$ of alginate) was incorporated into the solutions as a plasticizer, and it was mixed for $30 \mathrm{~min}$. Finally, $\mathrm{CaCO}_{3}(0.02 \mathrm{~g} / \mathrm{g}$ of alginate $)$ in combination with GDL $\left(5.4 \mathrm{~g} / \mathrm{g} \mathrm{CaCO}_{3}\right)$ was added as a source of calcium ions to initiate the gelation under constant stirring. GDL slowly hydrolyzes into gluconic acid and acidifies the 
Table 1 Composition of the alginate/roselle extract films

\begin{tabular}{lll}
\hline Film & $\begin{array}{l}\text { Alginate } \\
(\%, w / v)\end{array}$ & $\begin{array}{l}\text { Roselle } \\
\text { extract }(\%, \\
\text { w/v })\end{array}$ \\
\hline HE-0 & 1.5 & 0 \\
HE-1 & 1.5 & 1 \\
HE-3 & 1.5 & 3 \\
HE-5 & 1.5 & 5 \\
\hline
\end{tabular}

solution. Decreased $\mathrm{pH}$ increases the solubility of $\mathrm{CaCO}_{3}$ and releases calcium ions into the solution. Slow liberation of $\mathrm{Ca}^{2+}$ into the alginate matrix ensures a much stronger and more homogenous hydrogel overall. Film-forming solutions without $\mathrm{HE}$ were also produced. Each filmogenic dispersion was cast onto plastic Petri dishes and left to dry at room temperature for $48 \mathrm{~h}$. The dried films were stored in zip-lock bags at $4{ }^{\circ} \mathrm{C}$ until being used.

\section{Appearance and Thickness of the Films}

As the films were detached from the Petri dishes, their flexibility was evaluated qualitatively. The presence of cracks and bubbles in the films and the surface homogeneity were visually examined with the naked eye. Film thickness was determined using a digital micrometer (Mitutoyo, MDC25SX, Japan) with an accuracy of $0.001 \mathrm{~mm}$. Five different regions of each film formulation were measured, and average values were used in the WVP and mechanical tests.

\section{Mechanical Properties}

Tensile strength (TS) and elongation at break values (EB) of the films were determined using a universal testing machine (Shimadzu AGS-X, Japan). Sample films were cut into strips with dimensions of $1 \times 5 \mathrm{~cm}$. All the test specimens were conditioned for at least 3 days at room temperature prior to measurements. The initial gauge length was set to $20 \mathrm{~mm}$. Mechanical test measurements were reported as the average of at least four replicates for each type of film.

\section{Water Vapor Permeability}

WVP of the films was determined gravimetrically, as described by Benavides et al. [34], with slight modifications. Film samples were sealed onto permeability cups (VF2200 TQC, Netherlands) containing $10 \mathrm{~mL}$ of distilled water. The cups were put in a desiccator containing an oversaturated $\mathrm{NaCl}$ solution $(75 \% \mathrm{RH})$ to generate a $75 / 100 \%$ relative humidity gradient across the film. The desiccators were kept at $25^{\circ} \mathrm{C}$, and the weight of the cups were measured periodically (each $2 \mathrm{~h}$, for $8 \mathrm{~h}$ and at the end of $24 \mathrm{~h}$ ) using an analytical balance $( \pm 0.0001 \mathrm{~g})$. The measurements were replicated three times for each type of film, and WVP was calculated following Villalobos et al. [35].

\section{Water Content, Solubility, and Swelling Degree}

The water content, swelling degree, and solubility of film specimens were determined as described by Jamróz et al. [36]. Three randomly selected discs of $1.5 \mathrm{~cm}$ were removed from each type of film and weighed $\left(\mathrm{W}_{1}\right)$. Then the discs were dried in an oven $\left(70{ }^{\circ} \mathrm{C}\right)$ for $24 \mathrm{~h}$ to get the initial dry mass $\left(\mathrm{W}_{2}\right)$. Afterwards, the films were soaked in distilled water and kept at room temperature $\left(25 \pm 2{ }^{\circ} \mathrm{C}\right)$ for $24 \mathrm{~h}$. The swelled films were weighed $\left(\mathrm{W}_{3}\right)$ after excess water was removed, and they were dried in an oven at $70{ }^{\circ} \mathrm{C}$ for $24 \mathrm{~h}$. Lastly, the films were reweighed to determine the unsolubilized final dry mass $\left(\mathrm{W}_{4}\right)$. Water content, film solubility, and swelling degree were calculated according to the following equations.

Water content $=\left[\left(\mathrm{W}_{1}-\mathrm{W}_{2}\right) / \mathrm{W}_{1}\right] * 100 \%$,

Solubility $=\left[\left(\mathrm{W}_{2}-\mathrm{W}_{4}\right) / \mathrm{W}_{2}\right] * 100 \%$,

Swelling degree $=\left[\left(\mathrm{W}_{3}-\mathrm{W}_{2}\right) / \mathrm{W}_{2}\right] * 100 \%$.

\section{Scanning Electron Microscopy}

The microstructure of the film surfaces was investigated using a scanning electron microscope (SEM; Zeiss EVO 10, Germany). Each sample was coated with a thin gold-palladium film. Secondary electron imaging (SEI) mode was used to investigate the surface characteristics of the produced films.

\section{Fourier Transform Infrared Spectroscopy}

FTIR spectra of the film samples were recorded on a Thermo Scientific Nicolet i550 model spectrometer in the range of $4000-400 \mathrm{~cm}^{-1}$ at a resolution of $4 \mathrm{~cm}^{-1}$. FTIR spectra of the samples were used to determine possible interactions of functional groups in the produced films.

\section{Antibacterial Activity}

Antibacterial activity of pure alginate films and HE incorporated alginate films were tested against $E$. coli (ATCC 25922), S. aureus (ATCC 25923), Klebsiella pneumoniae (ATCC 700603), and Bacillus subtilis (ATCC 6633) via disc diffusion method. A colony of each bacteria was grown overnight in Nutrient broth and then diluted with saline to $10^{6} \mathrm{CFU} / \mathrm{mL}$. A total of $100 \mu \mathrm{L}$ of diluted bacteria were 
spread uniformly on nutrient agar plates, and films cut into circular discs with a diameter of $9 \mathrm{~mm}$ were placed on the inoculated plates. The films were sterilized under UV light for $10 \mathrm{~min}$ before tests. Nutrient agar plates were incubated at $37^{\circ} \mathrm{C}$ for $24 \mathrm{~h}$. Inhibition zones observed around the discs were measured in millimeters, and the experiments were performed in triplicate for all the test strains.

\section{Statistical Analysis}

IBM SPSS 22.0 software package was used to analyze the differences between alginate films with and without HE. One-way analysis of variance (ANOVA) was conducted to confirm the variability of the data and validity of the results. The least significant differences (LSD) were calculated at the $5 \%$ level $(p<0.05)$ to determine the differences between the mean values of the films' properties. A descriptive statistics test in the same program was used to calculate the standard errors of the means.

\section{Results and Discussion}

\section{Film Appearance}

Alginate films, prepared with or without HE, were uniform with no cracks or bubbles and were easily detached from the Petri dishes. As the films were cast onto Petri dishes, the surface of all films was smooth; however, a rough surface was observed for the films with HE after they were dried. The surface roughness of the dried films increased with higher concentrations of the extract.

Pure alginate films without HE were transparent, as shown in Fig. 1. The incorporation of $\mathrm{HE}$ in the alginate films caused a reddish color and the color deepened with increasing extract content. Color is an essential characteristic of a product that affects its appearance and also uses. Gómez-Aldapa et al. [26] prepared a corn starch film with roselle extract, and they also observed a red color that became more intense with increasing concentrations of the extract. The authors concluded that red-colored, opaque films might protect the food from ultraviolet and visible rays by reducing light exposure and thus delay food spoilage and extend shelf life.

\section{Film Microstructure}

Microstructures of pure alginate and HE incorporated alginate films prepared by the solvent casting method are represented in Fig. 2. The interactions between different components of the film-forming solution and how they interact during the drying period affect the microstructure of films. Pure alginate films showed a smooth and homogenous surface, whereas a rough and heterogeneous surface was observed for the alginate-HE composite films. The heterogeneity and roughness of the film surfaces were increased with increasing concentrations of HE. The smooth and regular surface of neat alginate films indicates an ordered arrangement of alginate chains within the film matrix. HE incorporated into the films may have disrupted the arrangement of polymer chains resulting in rough and irregular surfaces. Disruption of the arrangement of alginate chains by incorporation of HE may have also contributed to the increased thickness of the films (Table 2). Mango peel extract incorporated gelatin films [37], grapefruit seed extract reinforced chitosan films [38], and rosemary extract containing starchalginate composite films [39] also showed heterogeneous and/or rough surfaces upon addition of the extracts into the polymer matrices.

\section{Film Thickness}

Thickness is an essential attribute of edible films affecting mechanical and barrier properties. It is influenced by factors such as film preparation methods and drying conditions [40]. The thickness of pure alginate and alginate-HE composite films was between 25.9 and $109.2 \mu \mathrm{m}$ (Table 2). The results showed that pure alginate films had the lowest

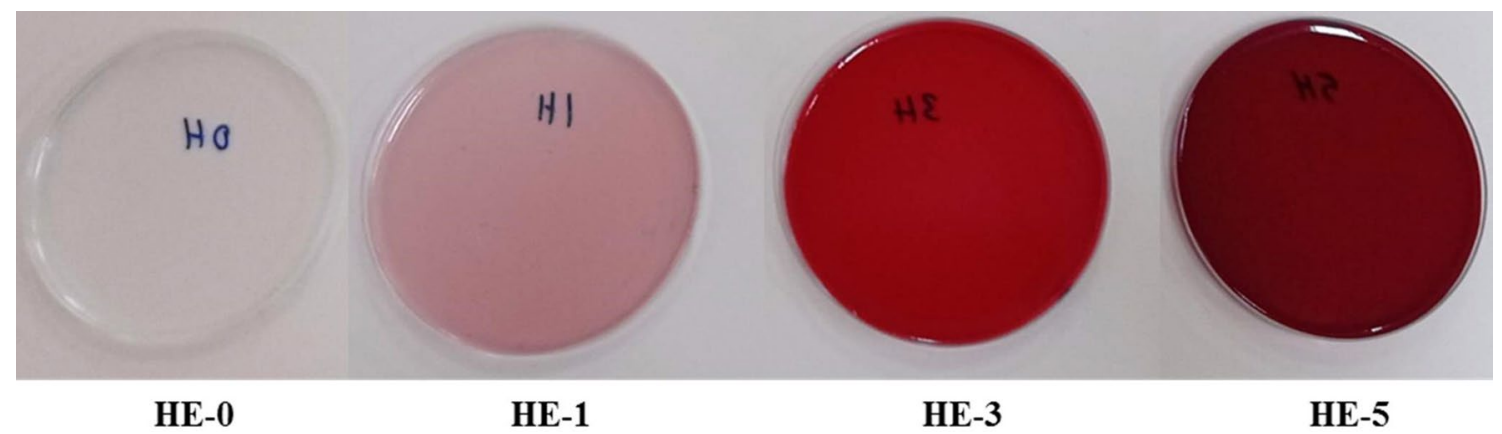

Fig. 1 Physical appearances of alginate/roselle extract films 
Fig. 2 SEM micrographs of alginate/roselle extract films. a HE-0, b HE-1, c HE-3, and d HE-5
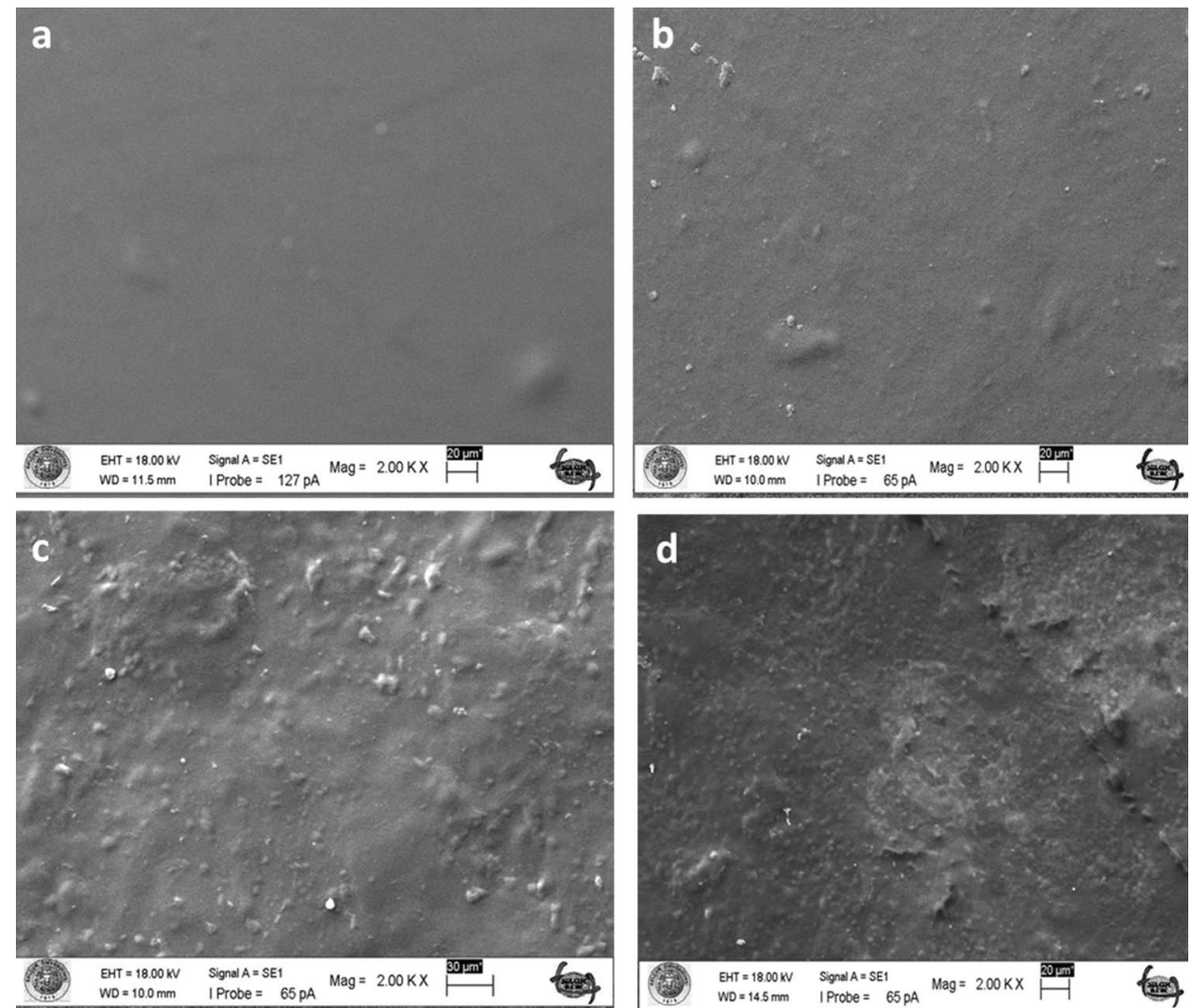

Table 2 Physical properties of alginate/roselle extract films

\begin{tabular}{lcllcl}
\hline & Film thickness $(\mu \mathrm{m})$ & Water content $(\%)$ & Solubility $(\%)$ & Swelling degree $(\%)$ & WVP $\left(\times 10^{-12} \mathrm{~g} / \mathrm{ms}\right.$ Pa $)$ \\
\hline HE-0 & $25.93 \pm 2.86 \mathrm{a}$ & $14.20 \pm 0.66 \mathrm{a}$ & $62.86 \pm 0.99 \mathrm{a}$ & $10,046.78 \pm 190.14 \mathrm{a}$ & $2.49 \pm 0.20 \mathrm{a}$ \\
$\mathrm{HE}-1$ & $46.53 \pm 5.52 \mathrm{~b}$ & $12.39 \pm 0.27 \mathrm{ac}$ & $32.22 \pm 1.69 \mathrm{~b}$ & $4591.42 \pm 134.31 \mathrm{~b}$ & $4.70 \pm 0.55 \mathrm{~b}$ \\
$\mathrm{HE}-3$ & $97.66 \pm 2.03 \mathrm{c}$ & $10.38 \pm 0.38 \mathrm{cb}$ & $50.92 \pm 1.99 \mathrm{c}$ & $1320.44 \pm 73.54 \mathrm{c}$ & $9.45 \pm 0.37 \mathrm{c}$ \\
$\mathrm{HE}-5$ & $109.20 \pm 1.25 \mathrm{~d}$ & $10.20 \pm 1.03 \mathrm{bd}$ & $65.76 \pm 1.47 \mathrm{a}$ & $484.19 \pm 74.33 \mathrm{~d}$ & $9.65 \pm 0.10 \mathrm{c}$
\end{tabular}

Data shown are the mean \pm standard error of the mean (SEM, $n \geq 3$ ). Similar letters in the same column indicate non-significant differences $(p<0.05)$

thickness. The incorporation of HE significantly $(p<0.05)$ increased the thickness of the composite films depending on the concentration of the extract. The gradual increase in thickness with increasing HE concentrations may be attributed to the conformational changes of alginate chains by the addition of extract and higher solid content. The compounds in HE may have disrupted the ordered alignment of the alginate chain and subsequently formed protruding structure within the alginate film matrix, as suggested by Adilah et al. [37]. Gómez-Aldapa et al. [26] also observed an increased thickness in the starch-based films containing HE when the HE: water volume ratio in the filmogenic solution was increased from 50:50 to 100:0. The findings of Luo et al. [22] were also in agreement with the results obtained in this study, which showed that the addition of guava leaf ethanolic extract in alginate film resulted in increased thickness. The authors suggested that greater thickness observed for the films with higher extract concentrations was due to the increased amount of solid content.

\section{Water Content, Solubility, and Swelling Degree of Films}

The water content of the films varied between 10.2 and $14.2 \%$ (Table 2). The water amount in composite films incorporated with $1 \% \mathrm{HE}$ was similar to the pure alginate film. However, when the HE content was higher than 3\%, the water content of films significantly $(p<0.05)$ decreased with the increase of extract content. HE- 3 and HE- 5 films were more brittle than HE- 0 and HE- 1 films which could be 
related to the lower water content of these films. The higher water amount present in HE-0 film may be due to the abundant carboxyl and hydroxyl groups in the alginate molecules. Hydroxyl groups in HE may interact with the hydrophilic groups in alginate upon adding the extract into alginate, which may limit alginate-water interaction. Similar data have been reported in the literature regarding reduced water content in films incorporated with various plant extracts [22, $23,41]$

An edible film/coating should not solubilize when it is used in humid conditions or utilized for packing foods with high moisture surfaces [42]. Sodium alginate, the most commonly used salt of alginate, is a water-soluble polymer. Applications of pure sodium alginate films are limited due to their high water solubility [42]. Cross-linking alginate films with polyvalent cations such as calcium is a common strategy to enhance physical, mechanical, and barrier properties $[34,43]$. Calcium ions induce conformational changes so that $\mathrm{G}$ blocks are arranged in a way that calcium ions exist between two sodium alginate chains forming divalent salt bridges. This arrangement is called the "eggbox" model [15, 43]. Cross-linking sodium alginate films with calcium significantly lowers the water solubility of alginate films [44]. Solubility of pure alginate and alginate-HE composite films ranged from 32.2 to $65.8 \%$ (Table 2). While the solubility of HE-5 films was similar to HE-0 films, HE-1 and HE-3 films represented significantly $(p<0.05)$ lower solubility with respect to HE-0 films. $\mathrm{CaCO}_{3}$ together with GDL was added to film-forming solutions for internal cross-linking of sodium alginate, and calcium alginate films were produced. When cross-linking was not applied, the films were totally solubilized in water (data not shown). Cross-linking significantly reduced the solubility of alginate films so that solubility of $62.9 \%$ was observed for pure calcium alginate films. The incorporation of HE further reduced the solubility of composite films, which was $32.2 \%$ for HE- 1 films and $50.9 \%$ for HE-3 films. Kim et al. [45] reported a decrease in solubility of red ginseng residue protein films containing $1 \%$ $\mathrm{HE}$, which is in good agreement with the results obtained in this study. Similarly, Adilah et al. [37] reported that the solubility of fish gelatin films incorporated with mango peels extract was decreased with increasing concentrations of the extract. The authors attributed the higher water resistance of the films to high protein-polyphenols interaction leading to a stronger film network structure. The interaction between HE polyphenols and alginate may have also led to the formation of a strong network, reducing alginate-HE films' solubility. Increased water resistance observed in these films indicates that they may be appropriate for the storage of foods.

The swelling of alginate-HE films was significantly lower $(p<0.05)$ with respect to pure alginate films (Table 2). Swelling of the composite films significantly decreased $(p<0.05)$ upon increasing concentrations of HE. Roger et al.
[46] suggested that carboxyl groups of alginate strongly interact with water molecules, affecting alginate's swelling behaviour. HE polyphenols interacting with carboxyl groups of alginate may have reduced the availability of these groups to water molecules. Thus increasing concentrations of HE may have limited the swelling ability of alginate-HE films.

\section{Water Vapor Permeability of Films}

WVP is an essential property for edible films/coatings, and a low water vapor transmission is desired for these products to ensure safe and prolonged food storage [47]. WVP of pure alginate films and alginate-HE composite films are represented in Table 2. The results revealed that WVP increased with increasing concentrations of HE. Several studies are available in the literature reporting increased WVP upon the addition of plant extracts into polymer matrices [3, 23, 25, 39]. In contrast to these reports, some studies reveal reduced WVP for the films incorporated with plant extracts [21, 22, $42,45,47]$. The intermolecular forces between the components of the films influence the WVP. Incorporation of plant extract might weaken the intermolecular interactions in the film network, and these changes in the internal structure of the films may favor solvent mobility and facilitate water diffusion in the polymeric matrix resulting in increased WVP $[3,23,25]$. Increased WVP observed in this study might also be attributed to the weakened intermolecular forces within the composite film matrix upon the addition of HE.

\section{FTIR Spectra of Films}

FTIR analyses were carried out to monitor specific functional groups and determine the possible chemical interactions between alginate and HE, which could help better understand the differences observed in the mechanical and physical properties of the films. FTIR spectra of pure alginate film and alginate films incorporated with different $\mathrm{HE}$ concentrations are given in Fig. 3. Pure alginate film exhibited five characteristic absorption bands around $3235 \mathrm{~cm}^{-1}$, $2929 \mathrm{~cm}^{-1}, 1592 \mathrm{~cm}^{-1}, 1404 \mathrm{~cm}^{-1}$, and $1021 \mathrm{~cm}^{-1}$. The broad band at $3235 \mathrm{~cm}^{-1}$ was attributed to the stretching vibration of the $\mathrm{OH}$ group, which participated in hydrogen bond formation [22]. The peaks observed at $1592 \mathrm{~cm}^{-1}$ and $1404 \mathrm{~cm}^{-1}$ were attributed to the asymmetric and symmetric stretching vibration of the $\mathrm{COO}$ groups, respectively [48]. These absorption bands can be overlapped with the band associated with the vibration of the $\mathrm{CH}$ group observed at $2929 \mathrm{~cm}^{-1}$ and $1404 \mathrm{~cm}^{-1}$ [24, 48]. A band at $1021 \mathrm{~cm}^{-1}$ representing $\mathrm{C}-\mathrm{O}-\mathrm{C}$ glycosidic bond stretching was also observed $[17,22]$. The spectra of the films with HE displayed similar transmittance peaks as pure alginate film. However, the absorption bands were significantly decreased and slightly shifted as the concentration of HE increased. 
Fig. 3 FTIR spectra of alginate/ roselle extract films

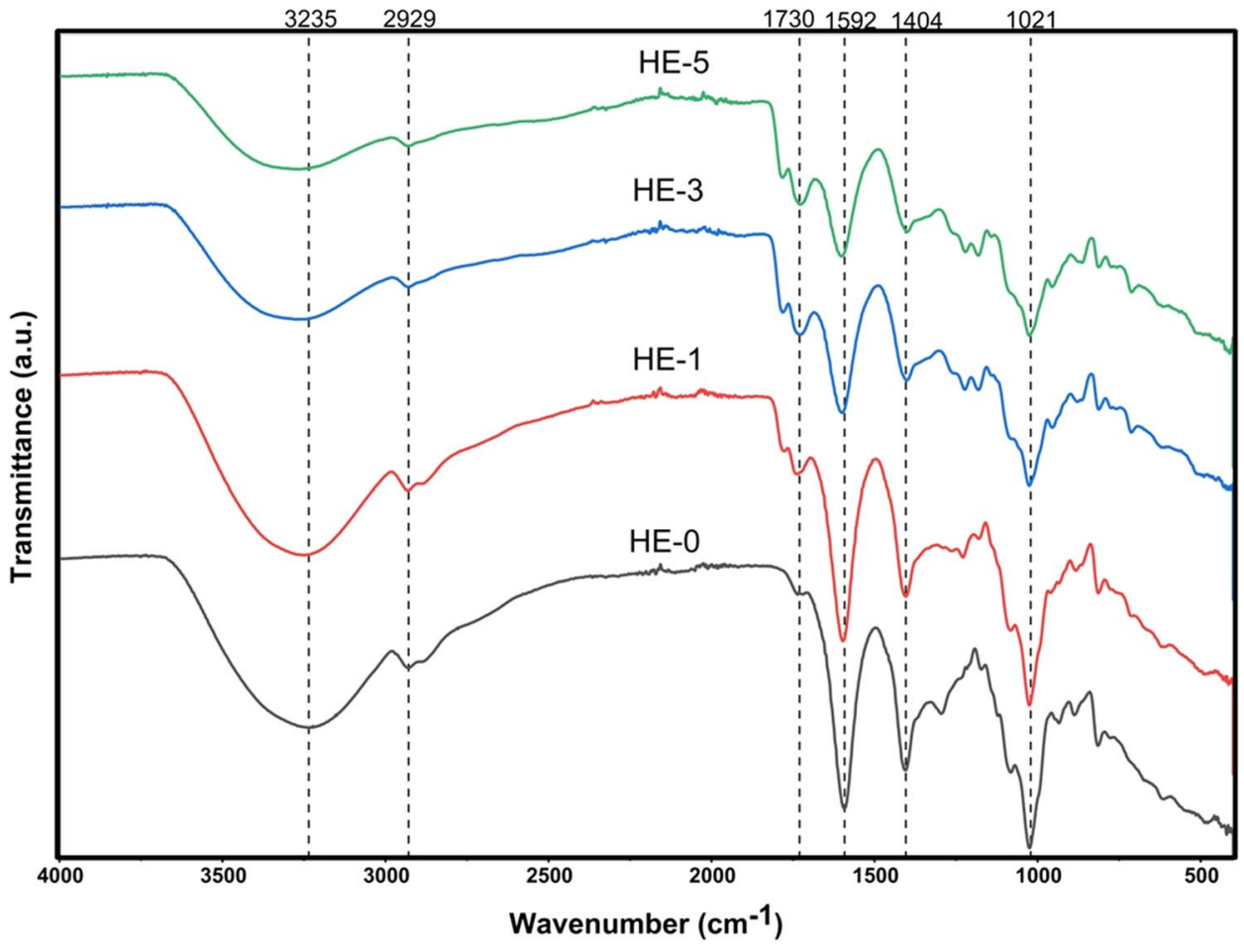

Table 3 Mechanical properties of alginate/roselle extract films

\begin{tabular}{lll}
\hline Film & TS $(\mathrm{MPa})$ & EB $(\%)$ \\
\hline HE-0 & $39.78 \pm 7.81 \mathrm{a}$ & $3.5 \pm 0.50 \mathrm{a}$ \\
HE-1 & $9.64 \pm 1.49 \mathrm{~b}$ & $1.17 \pm 0.05 \mathrm{~b}$ \\
HE-3 & $5.58 \pm 2.08 \mathrm{~b}$ & $0.83 \pm 0.1 \mathrm{~b}$ \\
HE-5 & NA & NA \\
\hline
\end{tabular}

Data shown are the means $( \pm$ SEM, $n=4)$. Similar letters in the same column indicate non-significant differences $(p<0.05)$

$N A$ not available

Previous studies attributed these changes to the establishment of hydrogen bonds between polyphenols and alginate [22]. In addition to the shifts and intensity variations observed in the alginate-HE films, two new peaks around $1730 \mathrm{~cm}^{-1}$ appeared, suggesting a possible interaction between alginate and HE.

\section{Mechanical Properties of Films}

TS and EB are two significant characteristics of food packaging materials that influence the capacity of films to endure external stress and keep integrity and barrier properties during handling, transportation, processing, and storage of food products [21]. Additives including water and plant extracts incorporated into polymeric films interact with the polymer and affect the TS and EB of the films [17]. Mechanical properties of alginate-based films are given in Table 3. For the pure alginate film, TS was $39.78 \mathrm{MPa}$. Although biopolymer films have poor mechanical properties compared to synthetic films, TS of pure alginate films obtained in this study was higher compared to cross-linked poly(vinyl alcohol) (PVA) membrane (27 MPa), which is a widely used synthetic polymer [49]. On the other hand, EB value for pure alginate film was $3.5 \%$ which was lower than the synthetic-based polymers, PLA membrane (8\%) [50], and Matrimid®5218 dense membrane (24\%) [51].

Compared to pure alginate films, the TS values of films with HE were significantly reduced $(p<0.05)$. However, there was no significant difference between HE-1 and HE-3 films. Increased HE content in the films caused a brittle structure, and it was not possible to measure the mechanical properties of HE-5 films as it was broken during attachment to the test machine. In accordance with the findings of this study, Kim et al. [45], Gómez-Aldapa et al. [26], and Zhai et al. [41] observed reduced TS upon addition of HE into red ginseng residue protein films, corn starch films, and starch/ polyvinyl alcohol films, respectively. The changes observed in TS of alginate-HE films are in agreement with the results of WVP and microstructure analysis. SEM images revealed heterogeneous and rough surfaces of films incorporated with $\mathrm{HE}$, which indicated a disrupted polymer chain arrangement. On the other hand, higher WVP observed for alginate-HE films suggested weakened intermolecular interactions in the film network. The disrupted arrangement of alginate chains and the weak intermolecular interactions in the film network due to the addition of HE may be responsible for the 
decrease in TS values. The EB values of HE-1 and HE-3 films were significantly lower $(p<0.05)$ compared to alginate films without HE. Contrary to these findings, EB was increased in red ginseng residue protein films [45], corn starch films [31], and starch/polyvinyl alcohol films [41] incorporated with HE. Zhai et al. [41] suggested that HE improved the compatibility of starch and PVA resulting in more homogenous starch/PVA films with increased extensibility. Gómez-Aldapa et al. [26] attributed the increased flexibility of corn starch films incorporated with HE to the interruption of the crystallinity of starch due to disruption of intermolecular $\mathrm{H}$ bonds within starch molecules, and the formation of $\mathrm{H}$ bonds between the extract and starch chains. On the other hand, Augusto et al. [52] observed a 23\% reduction in EB values for alginate films incorporated with Codium tomentosum seaweed extract, which is in accordance with the results of this study. The authors suggested that an equilibrium between the degree of polymer cross-linking and extract addition is vital for better film characteristics. Pereira et al. [53] also reported reduced EB value for alginate film incorporating Aloe vera gel at $12 \%$. A high concentration of A. vera extract was reported to increase the brittleness of the produced films, which was also observed in this study. The water content of alginate-HE films was lower than $(p<0.05)$ pure alginate films (Table 2), which may have contributed to the fragile structure of the HE incorporated alginate films. FTIR analysis indicated an interaction between the components of $\mathrm{HE}$ and alginate. The interaction between these compounds may have also caused a reduction in elongation of alginate-HE composite films.

\section{Antibacterial Activities of Films}

Antibacterial activities of pure alginate and alginate-HE films against Gram-positive (S. aureus and B. subtilis) and Gram-negative (E. coli and K. pneumoniae) test bacteria determined via disc diffusion method are represented in Table 4. Pure alginate film did not display any inhibitory effect on the test bacteria. These results are in accordance with those reported by de Oliveira Filho et al. [54] Moreover, alginate films incorporated with HE revealed good antibacterial activity that gradually increased with increasing $\mathrm{HE}$ concentrations. The growth-limiting effect of alginate-HE composite films was more pronounced against Gram-positive bacteria. The antibacterial activity of HE-3 and HE-5 films against $S$. aureus and $B$. subtilis was significantly higher $(p<0.05)$ than pure alginate films. On the other hand, the antibacterial effect of the composite films against $E$. coli and $K$. pneumoniae was significantly higher $(p<0.05)$ with respect to pure alginate films only when HE was incorporated at a concentration of 5\%. The common mechanism underlying the antibacterial effect of plant extracts is the penetration of the active compounds into the lipid bilayer of
Table 4 Inhibition zone diameter (including the $9 \mathrm{~mm}$ diameter of film discs) of alginate/roselle extract films

\begin{tabular}{lrrrr}
\hline Film & \multicolumn{4}{l}{ Inhibition zone diameter $(\mathrm{mm})$} \\
\cline { 2 - 5 } & \multicolumn{1}{l}{ S. aureus } & \multicolumn{1}{l}{ B. subtilis } & \multicolumn{1}{l}{ E. coli } & K. pneumoniae \\
\hline HE-0 & $9.00 \pm 0.00 \mathrm{a}$ & $9.00 \pm 0.00 \mathrm{a}$ & $9.00 \pm 0.00 \mathrm{a}$ & $9.00 \pm 0.00 \mathrm{a}$ \\
HE-1 & $10.00 \pm 1.00 \mathrm{a}$ & $10.66 \pm 1.66 \mathrm{a}$ & $9.00 \pm 0.00 \mathrm{a}$ & $9.00 \pm 0.00 \mathrm{a}$ \\
HE-3 & $19.33 \pm 0.33 \mathrm{~b}$ & $19.00 \pm 1.00 \mathrm{~b}$ & $11.00 \pm 2.00 \mathrm{ab}$ & $11.00 \pm 2.00 \mathrm{ab}$ \\
HE-5 & $22.00 \pm 1.00 \mathrm{c}$ & $21.66 \pm 1.33 \mathrm{~b}$ & $14.00 \pm 0.57 \mathrm{~b}$ & $14.00 \pm 0.57 \mathrm{~b}$ \\
\hline
\end{tabular}

Data are average values \pm standard error of the mean (SEM, $n=3$ ). Means in the same column followed by different letters are significantly different $(p<0.05)$

the cell membrane, which causes an increased membrane permeability with subsequent leakage of vital cell contents [55, 56]. Gram-negative and Gram-positive bacteria differ in their cell wall structure, affecting the interaction of these bacteria with antimicrobial compounds. Cell walls of Grampositive bacteria are composed of a peptidoglycan layer. In contrast, Gram-negative bacteria possess an additional lipopolysaccharide layer, the so-called outer membrane. The outer membrane surrounds both the cytoplasmic membrane and the peptidoglycan layer and restricts the penetration of small molecules like antibiotics [56, 57]. The lipopolysaccharide layer acting as a permeability barrier renders Gram-negative bacteria more resistant to plant-originated antimicrobials. The peptidoglycan cell wall of Gram-positive bacteria, although mechanically robust, poorly restricts diffusion of small molecules resulting in higher susceptibility of these organisms to plant extracts [56, 58].

Gómez-Aldapa et al. [26] investigated the antibacterial activity of corn starch films incorporated with aqueous extract of $H$. sabdariffa against four common foodborne pathogenic bacteria. They reported higher antibacterial activity depending on increasing HE concentration in accordance with the current study results. Portillo-Torres et al. [59] reported hibiscus acid to be one of the main antibacterial molecules in $H$. sabdariffa calyces. They suggested that hibiscus acid disrupted the membrane integrity and increased the permeability of cells to solutes resulting in an antibacterial effect against enterohemorrhagic E. coli EHEC A and Salmonella C65. In this study, hibiscus acid and other antimicrobial compounds in HE may have contributed to the antibacterial effect observed in alginate-HE composite films.

\section{Conclusion}

Alginate-based composite films incorporating $\mathrm{HE}$ as an antimicrobial agent were successfully produced via solvent casting technique. The FTIR spectra of the films verified that 
HE was immobilized into the alginate matrix. SEM investigations revealed a more rough and heterogeneous surface structure for the alginate-HE composite films compared to pure alginate films, which is possibly due to the disruption of the arrangement of alginate chains by incorporating HE. The water content, solubility, and swelling degree of the composite films significantly reduced with the increasing amounts of HE. The lower solubility of HE-1 and HE-3 films suggested that these films may be used in humid conditions or utilized for the packing of foods with high moisture surfaces. Moreover, alginate-based films showed a good antibacterial activity against Gram-negative and Gram-positive bacteria depending on the content of HE. The properties of the alginate/roselle extract films suggest that the films are promising to be used as a natural and degradable biopolymer-based composite packaging material for fresh vegetables and fruits. These materials produced from renewable sources may replace synthetic plastics that cause severe environmental pollution. Despite the eco-friendly nature of biopolymerbased packaging materials, their production costs are higher than conventional plastics limiting their widespread use. Competitiveness of these materials with synthetic plastics can be achieved by strategies such as improving the materials' properties or developing new production technologies.

Supplementary Information The online version of this article (https:// doi.org/10.1007/s12649-022-01710-3) contains supplementary material, which is available to authorized users.

Acknowledgements This research was financially supported by the Selcuk University Coordination of Scientific Research Projects (Project Number 19201103). The authors would like to express their gratitude to Dr. Aslihan Kurt Kizildogan (19 Mayis University, Samsun, Turkey) for supplying $E$. coli (ATCC 25922), S. aureus (ATCC 25923), K. pneumoniae (ATCC 700603), and B. subtilis (ATCC 6633) cells.

Data Availability Data will be available on request.

\section{Declarations}

Conflict of interest The authors declare no conflict of interest in publishing this manuscript.

\section{References}

1. Silva, A.L.P., Prata, J.C., Walker, T.R., Duarte, A.C., Ouyang, W., Barcelò, D., Rocha-Santos, T.: Increased plastic pollution due to COVID-19 pandemic: challenges and recommendations. Chem. Eng. J. 405, 126683 (2021)

2. Wright, S.L., Kelly, F.J.: Threat to human health from environmental plastics. Br. Med. J. (2017). https://doi.org/10.1136/bmj. j4334

3. Kim, S., Kang, J.-H., Song, K.B.: Development of a sword bean (Canavalia gladiata) starch film containing goji berry extract. Food Bioprocess Technol. 13, 911-921 (2020)
4. Hassan, B., Chatha, S.A.S., Hussain, A.I., Zia, K.M., Akhtar, N.: Recent advances on polysaccharides, lipids and protein based edible films and coatings: a review. Int. J. Biol. Macromol. 109, 1095-1107 (2018)

5. de Oliveira-Filho, J.G., Lemes, A.C., Braga, A.R.C., Egea, M.B.: Biodegradable eco-friendly packaging and coatings incorporated of natural active compounds. In: Food Packaging, pp. 171-206. CRC Press, Boca Raton (2020)

6. Díaz-Montes, E., Yáñez-Fernández, J., Castro-Muñoz, R.: Dextran/chitosan blend film fabrication for bio-packaging of mushrooms (Agaricus bisporus). J. Food Process. Preserv. 45(6), e15489 (2021)

7. Liu, P., Gao, W., Zhang, X., Wang, B., Zou, F., Yu, B., Lu, L., Fang, Y., Wu, Z., Yuan, C.: Effects of ultrasonication on the properties of maize starch/stearic acid/sodium carboxymethyl cellulose composite film. Ultrason. Sonochem. 72, 105447 (2021)

8. Díaz-Montes, E., Castro-Muñoz, R.: Edible films and coatings as food-quality preservers: an overview. Foods 10, 249 (2021)

9. Díaz-Montes, E., Castro-Muñoz, R.: Trends in chitosan as a primary biopolymer for functional films and coatings manufacture for food and natural products. Polymers 13, 767 (2021)

10. Díaz-Montes, E., Yáñez-Fernández, J., Castro-Muñoz, R.: Characterization of oligodextran produced by Leuconostoc mesenteroides SF3 and its effect on film-forming properties of chitosan. Mater. Today Commun. 28, 102487 (2021)

11. Terzioglu, P., Altin, Y., Kalemtas, A., Bedeloglu, A.C.: Graphene oxide and zinc oxide decorated chitosan nanocomposite biofilms for packaging applications. J. Polym. Eng. 40, 152-157 (2020)

12. Pérez-Guzmán, C.J., Castro-Muñoz, R.: A review of zein as a potential biopolymer for tissue engineering and nanotechnological applications. Processes 8, 1376 (2020)

13. Bahrami Feridoni, S., Khademi Shurmasti, D.: Effect of the nanoencapsulated sour tea (Hibiscus sabdariffa L.) extract with carboxymethylcellulose on quality and shelf life of chicken nugget. Food Sci. Nutr. 8, 3704-3715 (2020)

14. Huang, J., Chen, M., Zhou, Y., Li, Y., Hu, Y.: Functional characteristics improvement by structural modification of hydroxypropyl methylcellulose modified polyvinyl alcohol films incorporating roselle anthocyanins for shrimp freshness monitoring. Int. J. Biol. Macromol. 162, 1250-1261 (2020)

15. Senturk Parreidt, T., Müller, K., Schmid, M.: Alginate-based edible films and coatings for food packaging applications. Foods 7, 170 (2018)

16. Zam, W.: Effect of alginate and chitosan edible coating enriched with olive leaves extract on the shelf life of sweet cherries (Prunus avium L.). J. Food Qual. (2019). https://doi.org/10.1155/2019/ 8192964

17. Mahcene, Z., Khelil, A., Hasni, S., Akman, P.K., Bozkurt, F., Birech, K., Goudjil, M.B., Tornuk, F.: Development and characterization of sodium alginate based active edible films incorporated with essential oils of some medicinal plants. Int. J. Biol. Macromol. 145, 124-132 (2020)

18. Lee, K.Y., Mooney, D.J.: Alginate: properties and biomedical applications. Prog. Polym. Sci. 37, 106-126 (2012)

19. Abasalizadeh, F., Moghaddam, S.V., Alizadeh, E., Kashani, E., Fazljou, S.M.B., Torbati, M., Akbarzadeh, A.: Alginate-based hydrogels as drug delivery vehicles in cancer treatment and their applications in wound dressing and 3D bioprinting. J. Biol. Eng. 14, 1-22 (2020)

20. Gheorghita Puscaselu, R., Lobiuc, A., Dimian, M., Covasa, M.: Alginate: from food industry to biomedical applications and management of metabolic disorders. Polymers 12, 2417 (2020)

21. Aloui, H., Deshmukh, A.R., Khomlaem, C., Kim, B.S.: Novel composite films based on sodium alginate and gallnut extract with enhanced antioxidant, antimicrobial, barrier and mechanical properties. Food Hydrocoll. 113, 106508 (2021) 
22. Luo, Y., Liu, H., Yang, S., Zeng, J., Wu, Z.: Sodium alginatebased green packaging films functionalized by guava leaf extracts and their bioactivities. Materials 12, 2923 (2019)

23. Norajit, K., Kim, K.M., Ryu, G.H.: Comparative studies on the characterization and antioxidant properties of biodegradable alginate films containing ginseng extract. J. Food Eng. 98, 377-384 (2010)

24. Nascimento, K.M., Cavalheiro, J.B., Netto, A.Á.M., Da Silva Scapim, M.R., De Cássia Bergamasco, R.: Properties of alginate films incorporated with free and microencapsulated Stryphnodendron adstringens extract (barbatimão). Food Packag. Shelf Life 28, 100637 (2021)

25. Kim, S., Baek, S.-K., Song, K.B.: Physical and antioxidant properties of alginate films prepared from Sargassum fulvellum with black chokeberry extract. Food Packag. Shelf Life 18, 157-163 (2018)

26. Gómez-Aldapa, C.A., Díaz-Cruz, C.A., Castro-Rosas, J., JiménezRegalado, E.J., Velazquez, G., Gutierrez, M.C., Aguirre-Loredo, R.Y.: Development of antimicrobial biodegradable films based on corn starch with aqueous extract of Hibiscus sabdariffa L. StarchStärke (2021). https://doi.org/10.1002/star.202000096

27. Yang, Z., Zou, X., Li, Z., Huang, X., Zhai, X., Zhang, W., Shi, J., Tahir, H.E.: Improved postharvest quality of cold stored blueberry by edible coating based on composite gum Arabic/roselle extract. Food Bioprocess Technol. 12, 1537-1547 (2019)

28. Ali, B.H., Wabel, N.A., Blunden, G.: Phytochemical, pharmacological and toxicological aspects of Hibiscus sabdariffa L.: a review. Phytother. Res. 19, 369-375 (2005)

29. D'Souza, D.H., Dice, L., Davidson, P.M.: Aqueous extracts of Hibiscus sabdariffa calyces to control Aichi virus. Food Environ. Virol. 8, 112-119 (2016)

30. Doles, P., Babu, S.M., Ittera, N., John, I., John, L., John, N.: Tapioca starch based antimicrobial food packaging material. Int. J. Eng. Res. Technol. 3, 1051-1056 (2014)

31. Toro-Márquez, L.A., Merino, D., Gutiérrez, T.J.: Bionanocomposite films prepared from corn starch with and without nanopackaged Jamaica (Hibiscus sabdariffa) flower extract. Food Bioprocess Technol. 11, 1955-1973 (2018)

32. Abdelghany, A., Menazea, A., Ismail, A.: Synthesis, characterization and antimicrobial activity of Chitosan/Polyvinyl Alcohol blend doped with Hibiscus sabdariffa L. extract. J. Mol. Struct. 1197, 603-609 (2019)

33. Rasheed, D.M., Porzel, A., Frolov, A., El Seedi, H.R., Wessjohann, L.A., Farag, M.A.: Comparative analysis of Hibiscus sabdariffa (roselle) hot and cold extracts in respect to their potential for $\alpha$-glucosidase inhibition. Food Chem. 250, 236-244 (2018)

34. Benavides, S., Villalobos-Carvajal, R., Reyes, J.: Physical, mechanical and antibacterial properties of alginate film: effect of the crosslinking degree and oregano essential oil concentration. J. Food Eng. 110, 232-239 (2012)

35. Villalobos, R., Hernández-Muñoz, P., Chiralt, A.: Effect of surfactants on water sorption and barrier properties of hydroxypropyl methylcellulose films. Food Hydrocoll. 20, 502-509 (2006)

36. Jamróz, E., Juszczak, L., Kucharek, M.: Investigation of the physical properties, antioxidant and antimicrobial activity of ternary potato starch-furcellaran-gelatin films incorporated with lavender essential oil. Int. J. Biol. Macromol. 114, 1094-1101 (2018)

37. Adilah, A.N., Jamilah, B., Noranizan, M., Hanani, Z.N.: Utilization of mango peel extracts on the biodegradable films for active packaging. Food Packag. Shelf Life 16, 1-7 (2018)

38. Tan, Y., Lim, S., Tay, B., Lee, M., Thian, E.: Functional chitosanbased grapefruit seed extract composite films for applications in food packaging technology. Mater. Res. Bull. 69, 142-146 (2015)

39. Yan, Q., Zhang, J., Dong, H., Hou, H., Guo, P.: Properties and antimicrobial activities of starch-sodium alginate composite films incorporated with sodium dehydroacetate or rosemary extract. J. Appl. Polym. Sci. 127, 1951-1958 (2013)

40. Hosseini, S.F., Rezaei, M., Zandi, M., Farahmandghavi, F.: Fabrication of bio-nanocomposite films based on fish gelatin reinforced with chitosan nanoparticles. Food Hydrocoll. 44, 172-182 (2015)

41. Zhai, X., Shi, J., Zou, X., Wang, S., Jiang, C., Zhang, J., Huang, X., Zhang, W., Holmes, M.: Novel colorimetric films based on starch/polyvinyl alcohol incorporated with roselle anthocyanins for fish freshness monitoring. Food Hydrocoll. 69, 308-317 (2017)

42. Fabra, M.J., Falcó, I., Randazzo, W., Sánchez, G., López-Rubio, A.: Antiviral and antioxidant properties of active alginate edible films containing phenolic extracts. Food Hydrocoll. 81, 96-103 (2018)

43. Bekin, S., Sarmad, S., Gürkan, K., Yenici, G., Keçeli, G., Gürdağ, G.: Dielectric, thermal, and swelling properties of calcium ioncrosslinked sodium alginate film. Polym. Eng. Sci. 54, 1372-1382 (2014)

44. Santana, A.A., Kieckbusch, T.G.: Physical evaluation of biodegradable films of calcium alginate plasticized with polyols. Braz. J. Chem. Eng. 30, 835-845 (2013)

45. Kim, H., Yang, H.-J., Lee, K.-Y., Beak, S.-E., Song, K.B.: Characterization of red ginseng residue protein films incorporated with hibiscus extract. Food Sci. Biotechnol. 26, 369-374 (2017)

46. Roger, S., Talbot, D., Bee, A.: Preparation and effect of $\mathrm{Ca}^{2+}$ on water solubility, particle release and swelling properties of magnetic alginate films. J. Magn. Magn. Mater. 305, 221-227 (2006)

47. Medina Jaramillo, C., González Seligra, P., Goyanes, S., Bernal, C., Famá, L.: Biofilms based on cassava starch containing extract of yerba mate as antioxidant and plasticizer. Starch/Stärke 67, 780-789 (2015)

48. Pereira, R., Carvalho, A., Vaz, D.C., Gil, M.H., Mendes, A., Bártolo, P.: Development of novel alginate based hydrogel films for wound healing applications. Int. J. Biol. Macromol. 52, 221-230 (2013)

49. Castro-Muñoz, R., Buera-González, J., de la Iglesia, O., Galiano, F., Fíla, V., Malankowska, M., Rubio, C., Figoli, A., Téllez, C., Coronas, J.: Towards the dehydration of ethanol using pervaporation cross-linked poly (vinyl alcohol)/graphene oxide membranes. J. Membr. Sci. 582, 423-434 (2019)

50. Msahel, A., Galiano, F., Pilloni, M., Russo, F., Hafiane, A., Castro-Muñoz, R., Kumar, V.B., Gedanken, A., Ennas, G., Porat, Z.E.: Exploring the effect of iron metal-organic framework particles in polylactic acid membranes for the azeotropic separation of organic/organic mixtures by pervaporation. Membranes 11, 65 (2021)

51. Castro-Muñoz, R., Galiano, F., Fíla, V., Drioli, E., Figoli, A.: Matrimid ${ }^{\circledR} 5218$ dense membrane for the separation of azeotropic MeOH-MTBE mixtures by pervaporation. Sep. Purif. Technol. 199, 27-36 (2018)

52. Augusto, A., Dias, J.R., Campos, M.J., Alves, N.M., Pedrosa, R., Silva, S.F.: Influence of Codium tomentosum extract in the properties of alginate and chitosan edible films. Foods 7, 53 (2018)

53. Pereira, R., Tojeira, A., Vaz, D.C., Mendes, A., Bártolo, P.: Preparation and characterization of films based on alginate and Aloe vera. Int. J. Polym. Anal. Charact. 16, 449-464 (2011)

54. de Oliveira Filho, J.G., Rodrigues, J.M., Valadares, A.C.F., de Almeida, A.B., de Lima, T.M., Takeuchi, K.P., Alves, C.C.F., de Figueiredo Sousa, H.A., da Silva, E.R., Dyszy, F.H.: Active food packaging: alginate films with cottonseed protein hydrolysates. Food Hydrocoll. 92, 267-275 (2019)

55. Gonelimali, F.D., Lin, J., Miao, W., Xuan, J., Charles, F., Chen, M., Hatab, S.R.: Antimicrobial properties and mechanism of action of some plant extracts against food pathogens and spoilage microorganisms. Front. Microbiol. 9, 1639 (2018) 
56. Biswas, B., Rogers, K., McLaughlin, F., Daniels, D., Yadav, A.: Antimicrobial activities of leaf extracts of guava (Psidium guajava L.) on two gram-negative and gram-positive bacteria. Int. J. Microbiol. (2013). https://doi.org/10.1155/2013/746165

57. Martinez de Tejada, G., Sánchez-Gómez, S., Rázquin-Olazaran, I., Kowalski, I., Kaconis, Y., Heinbockel, L., Andra, J., Schurholz, T., Hornef, M., Dupont, A.: Bacterial cell wall compounds as promising targets of antimicrobial agents. I. Antimicrobial peptides and lipopolyamines. Curr. Drug Targets 13, 1121-1130 (2012)

58. Atef, N.M., Shanab, S.M., Negm, S.I., Abbas, Y.A.: Evaluation of antimicrobial activity of some plant extracts against antibiotic susceptible and resistant bacterial strains causing wound infection. Bull. Natl. Res. Cent. 43, 1-11 (2019)

\section{Authors and Affiliations}

\section{Gulsum Aydin ${ }^{1}$ [ Elif Busra Zorlu}

\author{
Gulsum Aydin \\ gkalemtas@gmail.com
}

59. Portillo-Torres, L.A., Bernardino-Nicanor, A., Gómez-Aldapa, C.A., González-Montiel, S., Rangel-Vargas, E., VillagómezIbarra, J.R., González-Cruz, L., Cortés-López, H., Castro-Rosas, J.: Hibiscus acid and chromatographic fractions from Hibiscus sabdariffa calyces: antimicrobial activity against multidrug-resistant pathogenic bacteria. Antibiotics 8, 218 (2019)

Publisher's Note Springer Nature remains neutral with regard to jurisdictional claims in published maps and institutional affiliations.

1 Biotechnology Department, Faculty of Sciences, Selcuk University, Konya, Turkey 